\title{
Analysis and Research on the Quality Detection of the Structural Entity of Civil Engineering Division in Lujiang's Gymnasium Ke-Wei DING ${ }^{1, a}$, Yong-Ming SUN ${ }^{2, b^{*}}$, Yang WANG ${ }^{3, c}$ \\ 1,2,3 School of Civil Engineering, Anhui Jianzhu University, Hefei 230601, PR China \\ adingkw@ahjzu.edu.cn, b478718817@qq.com, ${ }^{\circ} 562623194 @ q q . c o m$ \\ "Corresponding author
}

Keywords: Lujiang's Gymnasium, Civil Engineering Division, Detection.

\begin{abstract}
The detection results in the article are gained through tests on the material strength, reinforcement location, scantling design and slab thickness of civil engineering division of Lujiang's gymnasium. As for the substandard parts, treatment proposals are put forward to ensure the project quality.
\end{abstract}

\section{Project Overview}

Gymnasium in Anhui Lujiang's sports center demonstartes itself in steel structure for rectangular plane. It measures $79.2 \mathrm{~m}$ in width and $58.4 \mathrm{~m}$ in height, consisting of 12 models of the main truss, 10 specimens of Zhicheng truss, 4 pin edge truss. Inside, the halfmoon supports the system and conical steel structure makes the roof.

The upper steel structure bearing sits in the top of the lower part of the reinforced concrete column and they are connected by a pre-buried bolt. Currently the civil engineering is completed in the mian, followed by successive welding of steel structure elements. The plan is shown below.

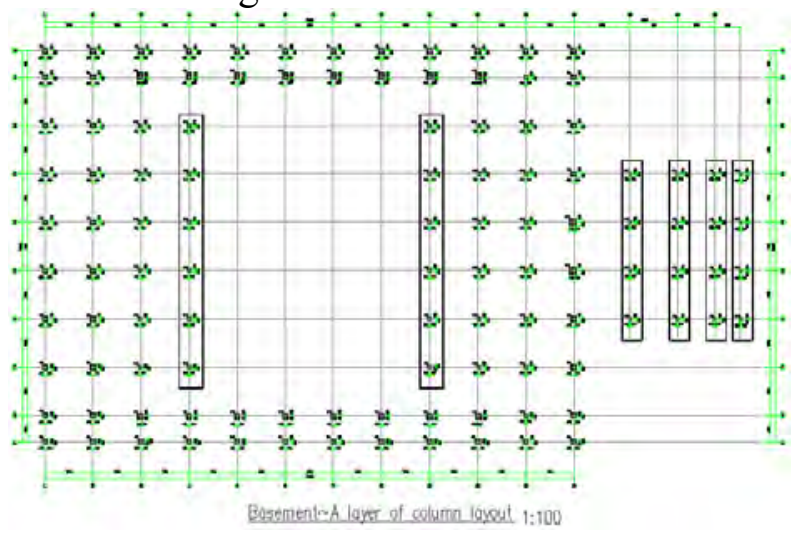

Fig. 1 Basement $\sim$ A Layer of Column Layout

\section{Test Content and Equipment}

The test is authorized by the Bureau of Housing and Construction of Lujiang County. The strength of beams, boards, columns and concrete, the thickness of boards, the sectional reinfoecement allocation and the thickness of cover have been tested through applying device of ZBL-S210 digital concrete resiliometre,ZBL-U510 nonmetal ultrasonic detector, SW-180 reinforced position detector, NJJ-95B concrete radar detector, ZBL-T720 slab thickness tester and steel tape.

\section{Testing Process and Result Evaluation of Beams, Boards and Columns}

In the testing course, beams, boards and columns of the gymasium were randomly examined to inspect the quality of the structure is qualified or unqualified through the comparison of the surveillance and design standard. Any unqualifued parts were given treatment proposals in order to 
ensure the construction project.

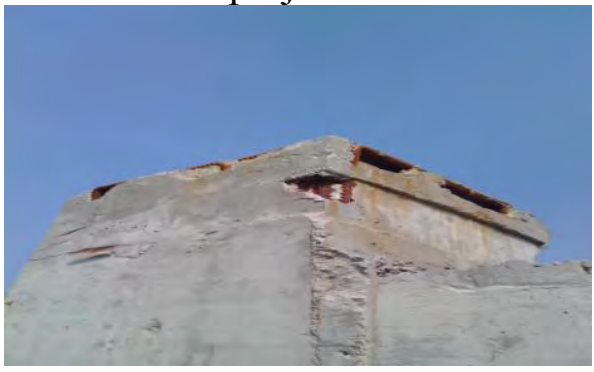

Fig. 2 Stigma

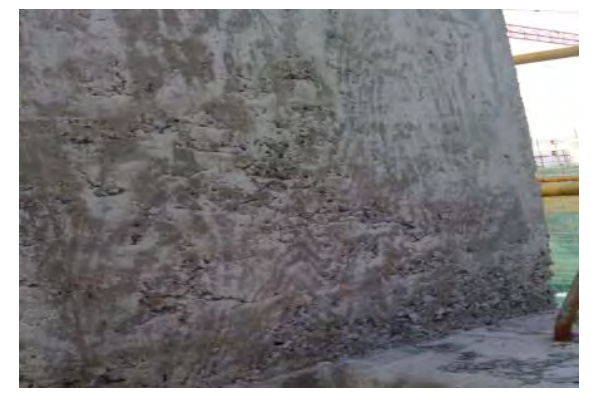

Fig. 4 Cylindrical

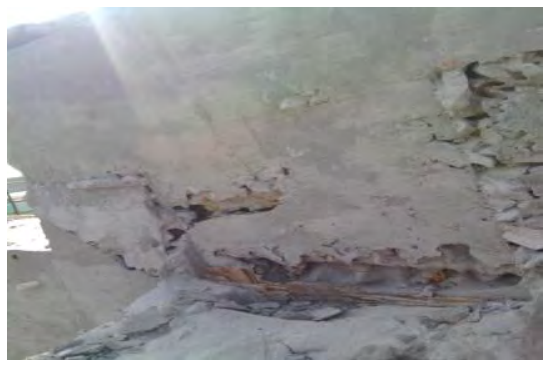

Fig. 3 Beam-column Joints

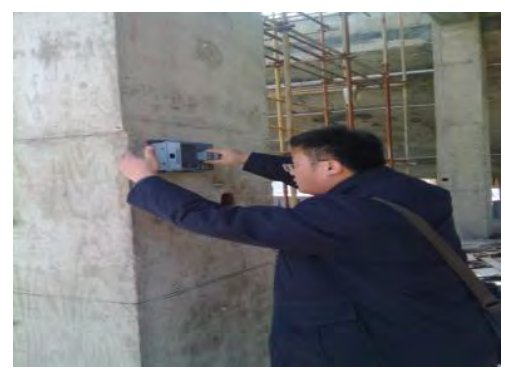

Fig. 5 Using the Concreterebound Hammer to Test the Concrete Strength

Tab. 2-1 Column Evaluation of First Layer

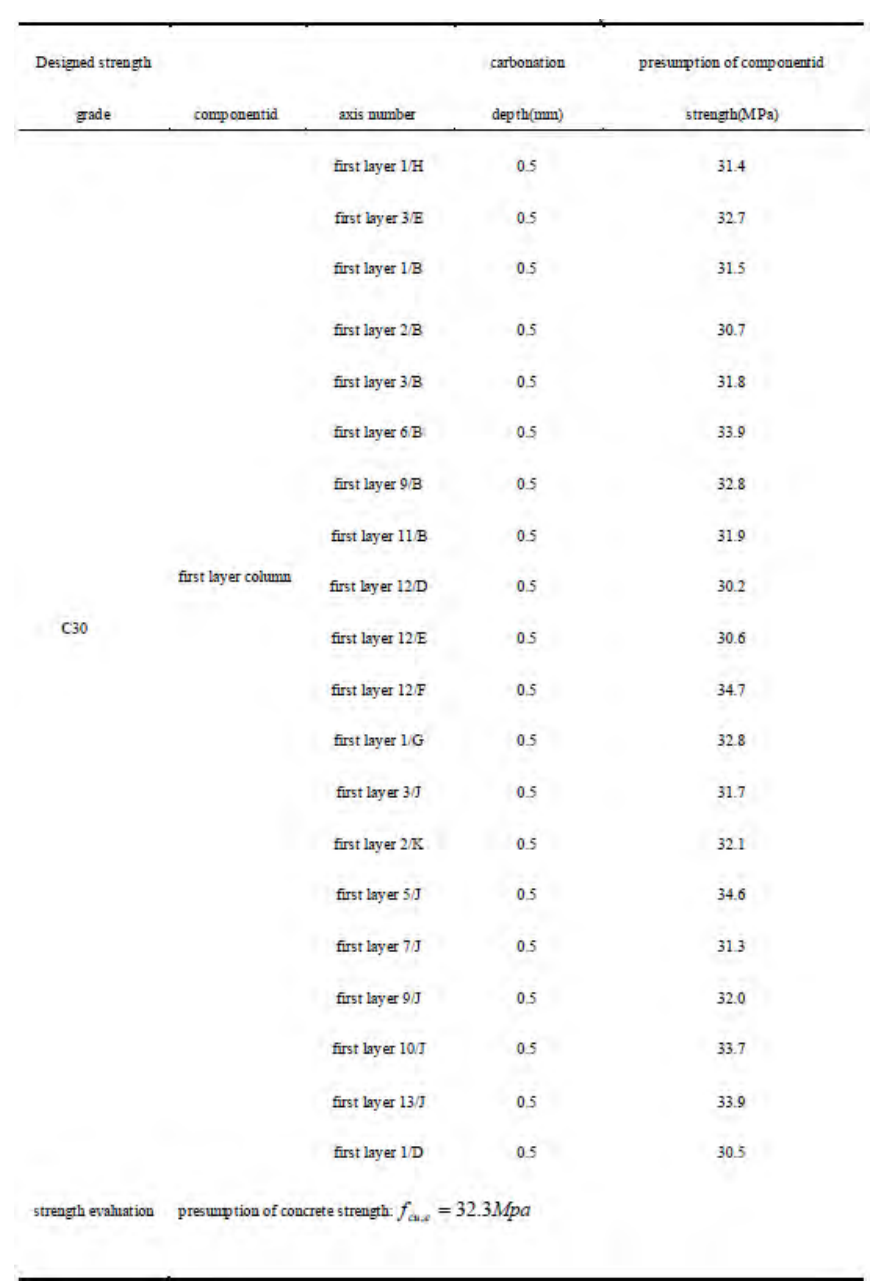


Tab. 2-2 Column Evaluation of Second Layer

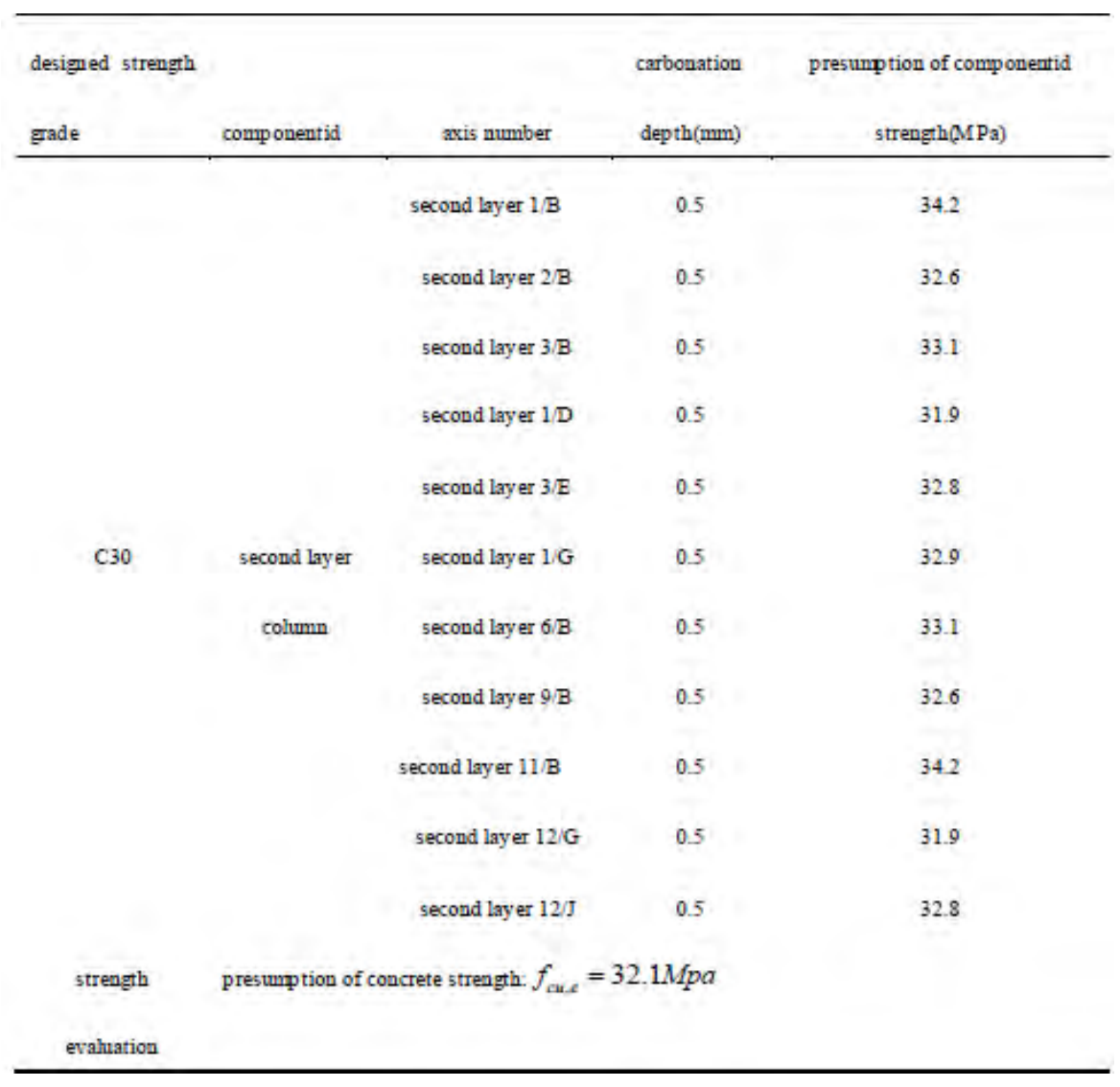

Tab. 2-3 Board Thickness Evaluation

\begin{tabular}{|c|c|c|c|c|c|}
\hline components & axial position & design & measured & deviation(mm) & test resuli \\
\hline & & requirements & distance $(\mathrm{mm})$ & & \\
\hline roof of the first & $12-1 / 13-\mathrm{H}-\mathrm{I}$ & $\mathrm{H}=120$ & 123 & +3 & compliance \\
\hline layer & & & & & desigg \\
\hline roof of the first & $12-1 / 13-\mathrm{H}-$ & $\mathrm{H}=120$ & 116 & -4 & compliance \\
\hline layer & G & & & & design \\
\hline roof of the first & $12-1 / 13-C-$ & $H=120$ & 113 & -7 & noncompliance with \\
\hline layer & D & & & & design \\
\hline roof of the first & $10-11 / A-O$ & $\mathrm{H}=120$ & 123 & +3 & compliance \\
\hline layer & & & & & design \\
\hline Toof of the first & $4-5 / A-0$ & $\mathrm{H}=120$ & 127 & +7 & compliance \\
\hline layer & & & & & desigg \\
\hline roof of the first & $0-1 / C-D$ & $\mathrm{H}=120$ & 121 & +1 & compliance \\
\hline layer & & & & & design \\
\hline roof of the first & $0-1 / G-H$ & $\mathrm{H}=120$ & 112 & -8 & noncompliance with \\
\hline layer & & & & & design \\
\hline roof of the second & $11-12 / \mathrm{H}-\mathrm{G}$ & $\mathrm{H}=120$ & 118 & -2 & compliance \\
\hline layer & & & & & design \\
\hline roof of the second & $10-11 / \mathrm{K}-\mathrm{J}$ & $\mathrm{H}=120$ & 106 & -14 & noncompliance with \\
\hline layer & & & & & design \\
\hline
\end{tabular}


Tab. 2-4 Top-beam Evaluation of Second Layer

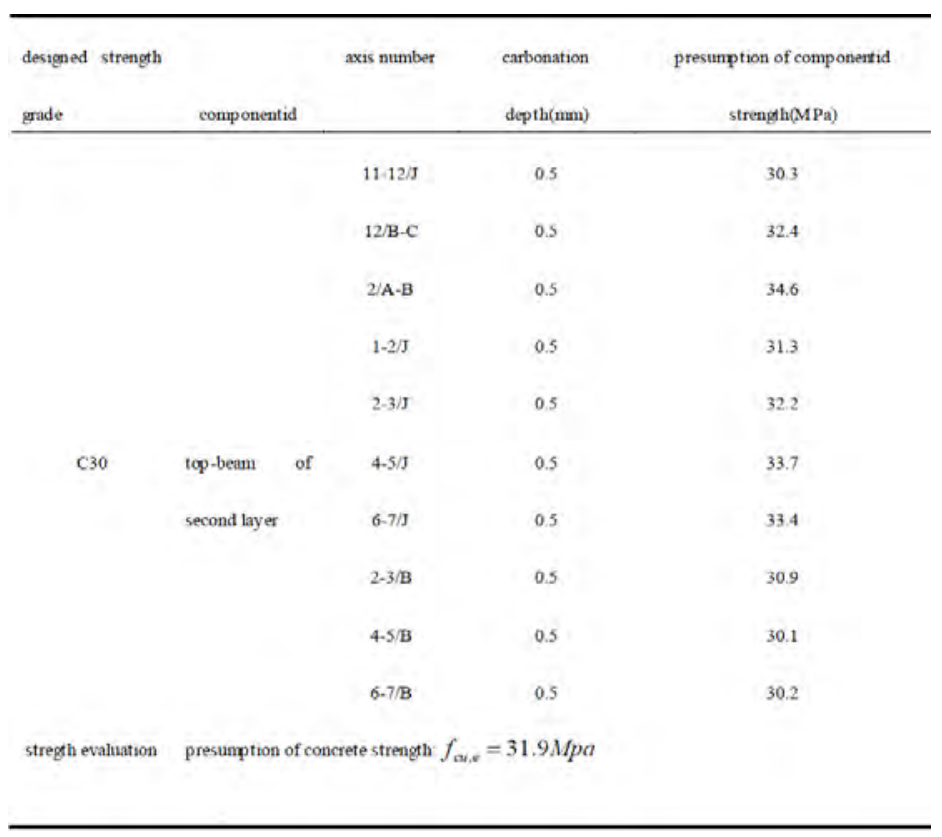

Tab. 2-5 Roof Board Evaluation of First Layer

\begin{tabular}{|c|c|c|c|c|}
\hline designed strength & & & carbonation & presumption of componentid \\
\hline \multirow[t]{2}{*}{ grade } & componentid & axis number & $\operatorname{depth}(\mathrm{mm})$ & strength(MPa) \\
\hline & roof of first layer & G-H/11-12 & 0.5 & 32.6 \\
\hline \multirow[t]{2}{*}{$\mathrm{C} 30$} & & A-B/8-9 & 0.5 & 33.8 \\
\hline & & $\mathrm{K}-\mathrm{L} / 8-9$ & 0.5 & 34.0 \\
\hline stregth & \multicolumn{4}{|c|}{ presumption of concrete strength: $f_{c u, e}=31.9 \mathrm{Mpa}$} \\
\hline evaluation & & & & \\
\hline
\end{tabular}

Tab. 2-6 Evaluation of Column Stirrup Spacing

\begin{tabular}{|c|c|c|c|c|c|}
\hline components & axial & design requirements & measured & deviation $(\mathrm{mm})$ & test result \\
\hline & position & & distance(mm) & & \\
\hline \multirow[t]{3}{*}{ second layer } & $12 / \mathrm{G}$ & $\Phi 10 @ 200$ & 216 & +16 & noncompliance with \\
\hline & & (non encrypted & & & design \\
\hline & & area) & & & \\
\hline \multirow[t]{2}{*}{ first layer } & $12 / \mathrm{G}$ & $\Phi 10 @ 200$ (non & 174 & -26 & compliance \\
\hline & & encrypted area) & & & design \\
\hline \multirow[t]{2}{*}{ first layer } & $12 / \mathrm{F}$ & $\Phi 12 @ 100$ & 101 & +1 & compliance \\
\hline & & (Encryption area) & & & design \\
\hline \multirow[t]{2}{*}{ first layer } & $12 / \mathrm{D}$ & Ф10@200（non & 190 & -10 & compliance \\
\hline & & encrypted area) & & & design \\
\hline
\end{tabular}


Tab. 2-7 Negative Reinforcement Spacing Evaluation of Second Layer

\begin{tabular}{|c|c|c|c|c|c|}
\hline \multirow[t]{2}{*}{ components } & axial position & design & measured & deviation( & test result \\
\hline & & requirements & distance $(\mathrm{mm})$ & \multicolumn{2}{|l|}{$\mathrm{mm})$} \\
\hline \multirow{4}{*}{ second layer } & $11-12 / \mathrm{G}-\mathrm{H}$ & (a)200 & 197 & -3 & compliance with design \\
\hline & $10-11 / \mathrm{J}-\mathrm{K}$ & @200 & 197 & -3 & compliance with design \\
\hline & $8-9 / \mathrm{K}-\mathrm{L}$ & @200 & 204 & +4 & compliance with design \\
\hline & $8-9 / \mathrm{J}-\mathrm{K}$ & (a) 200 & 224 & +4 & compliance with design \\
\hline
\end{tabular}

Tab. 2-8 Evaluation of Protective Layer of the Mian Reinforcement of the Column

\begin{tabular}{|c|c|c|c|c|c|}
\hline components & axial position & protective layer & measured & deviation( & test result \\
\hline & & design & distance $(\mathrm{mm})$ & $\mathrm{mm})$ & \\
\hline second layer column & $12 / \mathrm{G}$ & 30 & 24 & -6 & l \\
\hline first layer column & $12 / \mathrm{G}$ & 30 & 30 & 0 & l \\
\hline first layer column & $12 / \mathrm{F}$ & 30 & 22 & -8 & l \\
\hline first layer column & $12 / \mathrm{D}$ & 30 & 15 & -15 & / \\
\hline
\end{tabular}

\section{Treatment Result}

\section{Concrete Strength Examination Result of Randomly Selected Beams, Boards and Columns}

(1) The presumed concrete strength value of the randomly selected columns in first layer is 32.3MPa. It meets the requirement of the designed strength of $\mathrm{C} 30$.

(2) The presumed concrete strength value of the randomly selected columns in second layer is 32.1 MPa. It meets the requirement of designed strength of $\mathrm{C} 30$.

(3) The presumed concrete strength value of the randomly selected top-beams in second layer is $31.9 \mathrm{MPa}$. It meets the requirement of designed strength of $\mathrm{C} 30$.

(4) The persumed concrete strength value of the randomly selected top-boards in first layer is $32.6 \mathrm{MPa}$. It meets the requirement of designed strength of $\mathrm{C} 30$.

\section{The Reinforcement Allocation Evaluation Result of Randomly Selected Beams, Boards and Columns}

The stirrup spacing and the mian rib root number of the selected frame beams and columns basically meet the design requirements. The node spacing of stirrups and protective layer thickness basically meet the design requirements.

\section{The Slab Thickness Evaluation Result}

The thickness of the randomly selected slabs basically meet the design requirements. 


\section{The Appearance Quality of the Structure Evaluation Result}

(1) Serious cases of boxwork, pitting surface, reinforcement exposure and corrosion have been detected in parts of the top-column joints.

(2) Between the pre embedded steel and the top of the top columns, breakoff phenomenon,slits of uneven width,reinforcement exposure and corrosion have been detected.

(3) Uncompacted concrete, reinforcement eposure are general phenomenon at the top of the static pressure box structure pole.

(4) Reinforcement exposure and corrosion have been detected at the bottom of some beams.

\section{Treatment Proposals}

(1) The breakoff between the pre embedded steel and the top of the top columns makes it detrimental for top column to bear the upper load of steel structure.

(2) As for the boxwork and pitting surface in column joints, hign strength mortar is suggested to be used.

(3) Rust cleaning in column joints and reinforcement exposure is necessary, which should be accompanied by the use of high strength mortar.

(4) As for the big danger hidden in the loose junction between the static pressure box structure pole and beams, high strength micro expansion mortar can be wiped in the junction to avoid corrosion of the tensile reinforcement. Meantime, the boom should be reinforced to enhance the reliability of the upper and lower end of connecting node.

\section{Acknowledgements}

This project is supported by Anhui Soft science (No.1302053055) and Anhui Provincial Laboratory Project Funding through grant No. 1106c0805024.

\section{Reference}

[1]JGJ/T 23-2011,Inspection of concrete strength by rebound method and technology standard [S].China Architecture \& Building Press,2011.

[2]CECS 02-2005, Technical specification for testing concrete strength by ultrasonic rebound combined method [S]. China Plan Publishing Company,2005.

[3]JGJ/T 152-2008,Technical specification for inspection of steel bar in concrete [S].China Architecture \& Building Press,2008.

[4]GB50202-2002(The 2011 Edition), Code for acceptance of construction quality of concrete structure [S].China Architecture \& Building Press,2011. 